\title{
Spectrophotometric determination of phenolic antioxidants in four varieties of apples (Pyrus malus) from Balochistan, Pakistan
}

\author{
Atta Muhammad, Attiq-Ur-Rehman, Naqeebullah Khan, Samiullah*, \\ Muhammad Asghar, Abdul Baqi, Abdullah Jan zeerak, Mohammad \\ Hussain and Hayatullah \\ Department of Chemistry, University of Balochistan, Quetta, 87300-Pakistan \\ *Corresponding author's email: sami435889@yahoomail.com
}

Citation

Atta Muhammad, Attiq-Ur-Rehman, Naqeebullah Khan, Samiullah, Muhammad Asghar, Abdul Baqi, Abdullah Jan zeerak, Mohammad Hussain and Hayatullah. Spectrophotometric determination of phenolic antioxidants in four varieties of apples (Pyrus malus) from Balochistan, Pakistan. Pure and Applied Biology. Vol. 8, Issue 1, pp768-779. http://dx.doi.org/10.19045/bspab.2019.80019

\begin{tabular}{llll}
\hline \hline Received: 23/11/2018 & Revised: 10/01/2019 & Accepted: 16/01/2019 & Online First: 25/01/2019 \\
\hline
\end{tabular}

\section{Abstract}

Apples (Malus domestica Borkh) are the good source of phenolic compounds and antioxidants, which are not only potential nutrients but also effective in chronic diseases. Four famous varieties of apple namely Shin Kulu, Amri, Kaja, and Tor Kulu from different areas of Balochistan province were collected and analyzed for phenolic contents and antioxidant activities in methanol-water $(80: 20 \%(\mathrm{v} / \mathrm{v}))$ extract by using standard spectrophotometric methods. The results of average extract yields of the antioxidant component obtained in dry weights (dw) of both peel and pulp were found $27.3 \pm 0.52 \mathrm{~g} / 100 \mathrm{~g}$ and $19.1 \pm 0.21 \mathrm{~g} / 100 \mathrm{~g}$ respectively. The different varieties of apples contain quantity of entire phenolics content on apple peel and pulp ranged from $13.12 \pm 0.22 \mathrm{mg}$ to $17.87 \pm 0.10 \mathrm{mg} \mathrm{GAE} / \mathrm{g} \mathrm{dw}$ for peel and $7.21 \pm 0.10 \mathrm{mg}$ to $11.57 \pm 0.08 \mathrm{mg} \mathrm{GAE} / \mathrm{g} \mathrm{dw}$ for pulp and total flavonoids content were found from $12.22 \pm 0.11 \mathrm{mg}$ to $15.30 \pm 0.18 \mathrm{mg} \mathrm{CE} / \mathrm{g} \mathrm{dw}$ for peel and $6.01 \pm 0.03 \mathrm{mg}$ to $9.69 \pm 0.14 \mathrm{mg} \mathrm{CE} / \mathrm{g} \mathrm{dw}$ for pulp. The variations in reducing power of the $10 \mathrm{mg} / \mathrm{mL}$ were ranged in peel from 2.139 to 2.725 and pulp from 1.181 to 1.724 . The variations in the inhibition of DPPH scavenging activity of the $80 \%$ methanolic extracts were seen from $79.6 \%$ to $67.6 \%$ in peel and $57.8 \%$ to $41.2 \%$ in pulp. The variations were also found on the basis of genotype, soil fertility, care of watering and climate of the area. The results reveal high concentration of phenolics content, flavonoids content and antioxidant capacity in peel than pulp, so the consumption of peel with fruit might be strongly recommended to achieve better nutritional benefits.

Keywords: Antioxidant activity; Apple peel; DPPH; Flavonoids; Phenolics; Pulp

Introduction

During the normal cellular metabolism molecular species with unpaired electrons are formed, which are unstable, short lived and highly reactive inside body of living organism, are called free radicals [1], which 
behave like oxidants or reductants. These chemical species usually trigger chain reactions, which damage the body cells of the living organism. Reactive Oxygen Species (ROS) and Reactive Nitrogen Species (RNS) are the most important pro-oxidant/oxidants (free radicals) which are formed during metabolic reactions, due to their harmful effects. Several harmful chemical compounds are formed in a human body [2]. The ROS results in the production of abnormal cells and tissues due to the oxidation of poly-unsaturated fatty acids of the cell membranes. Excess of free radical formation (ROS/RNS) and having less antioxidant defenses causes imbalance, so due to high concentration and high reactive nature of free radical oxidative stresses are produced, which further react with other important bio-molecules such as proteins, DNA, cell membrane, nucleic acids and lipids [3]. These stresses initiate diseases like cancer, cardiovascular, arthritis, diabetes, emphysema, cirrhosis and ageing $[4,5]$. Free radicals in the form of ROS are either generated endogenously in internal cellular organs like mitochondria, endoplasmic reticulum and peroxisomes [6] or exogenously due to alcohol, cigarette smoking, transition metals like $\mathrm{Cd}, \mathrm{Hg}, \mathrm{Pb}$, As, Co etc, pesticides, UV rays, high temperature, smoked or fried fatty meat and drugs [7].

Antioxidants are the chemical compounds that quench the reactions of free radicals by reducing their oxidation processes [8] and providing universal defensive mechanism for cells against many chronic diseases $[9,10]$. Dietary source of antioxidants participates an essential job for a person's general health because the fact that the living bodies require a large number of antioxidants than having the capability to generate them [11]. On the basis of activity, antioxidants are categorized into two types, enzymatic antioxidants and non-enzymatic antioxidants. The former, in the presence of cofactors such as zinc, copper, iron, manganese etc, break down and remove the free radical by changing them into hydrogen peroxide and last into water through a series of reactions. The later, include vitamin $\mathrm{C}$, Vitamin $\mathrm{E}$ and plant phenolics, carotenoids, glutathione and other phytonutrients present in vegetables and fruits, which interrupt the chain reactions of the free radicals $[12,13]$. Fruits have the excess amounts of flavonoids, phenolic acids, vitamins, minerals and valuable strong antioxidants [14]. The presence of antioxidants in fruit depend on the types of fruits, gardening condition and climate of the area and as well as in the different parts of fruit such as peel or pulp. Peels of most of fruits contain much phenolic contents and show higher antioxidants activity than the pulp [16]. The fruits contain a greater number of antioxidants like vitamin $\mathrm{C}, \mathrm{E}$, polyphenols, $\beta$-carotene and lycopene [17]. Apple (Malus domestica Borkh) is rich source of many types of phytonutrients such as phenolic compounds which are effective antioxidants [18]. The most interesting feature is that apple contains the biggest portion of free phenolics as compared to other fruits. So, these bioactive substances are more easily absorbed [19]. About $80 \%$ of polyphenolic compounds and 3 to 6-fold of total flavonoids are distributed in the peel of apples [20]. The apple flesh contains catechin, procyanidin, chlorogenic acid, phloridzin and caffeic acid. The peel of apple contains additional compounds, like quercetin and cyanidin, which are not present in the pulp [21].

Apples are the best sources of vitamin $\mathrm{C}$ and fibers [22] and therefore may decrease weight if utilize before meals, support heart health in several ways and lower the cholesterol level [23]. The epicatechin a type of polyphenols, present in apples, linked to decrease blood pressure hence stroke risk [24]. Apple fiber pectin can speed up the 
movement of the stool through the intestines, decrease the symptoms of constipation and increase the number of useful bacteria in the gut and also protects from colon cancer [25]. The consumption of apple flavonoids may decrease the cardiovascular diseases (CVD) risk, obesity and diabetes [26]. Apples peel contain quercetin a type of flavonoids which work as antioxidant and anti-inflammatory and helps to normalize immune system and give protection against disease like asthma [27]. Medical science studies proved that the usual consumption of apple with peel decreases the cancer risk of colon [28], regulates the amounts of calcium mineral which helps to support bone health [29] and acetylcholine, a neurotransmitter, which prevents Alzheimer's disease [30].

In Pakistan, Balochistan province is the largest producer of fruits, therefore, known as "Fruit basket of Pakistan" with annual apples production of 224000 tons. Apple contributing over $23 \%$ of total production of the country [31]. Apple producing areas in the highland of Balochistan comprising Mastung, Kalat, Quetta, Pishin, Ziarat, Killa Abdullah, Killa Saifullah, Loralai and Zhob districts. Several varieties of apples are grown in these districts and the commonly grown commercial varieties include Kaja, Tor Kulu, Shin Kulu, Amri, Mashadi and Kashmiri [32]. Tor Kulu apple accounts for about $35 \%$ of apple produced in Balochistan. It is fragrant, juicy and crispy with rational size. Shin Kulu apple fruit is popular due to its juicy flavor with acidic sweet taste and accounts for about $40 \%$ of apple produced in Balochistan [33].

\section{Materials and methods}

All analytical grade chemicals and reagents were used. Methanol, potassium ferricyanide, trichloroacetic acid (ACS reagent), $\mathrm{FeCl}_{3}$, $\mathrm{Na}_{2} \mathrm{CO}_{3}, \mathrm{AlCl}_{3}, \mathrm{NaNO}_{2}$ and $\mathrm{NaOH}$ which were purchased from Merck (Darmstadt, Germany) Folin-Ciocalteu Reagent (FCR), gallic acid, 2,2-diphenyl-1-picrylhydrazyl
(DPPH) radical, catechin and ascorbic acid were obtained from Sigma Aldrich (Buchs, Switzerland).

A homogenizer used for homogenizing sample (Westpoint-1844-Juicer-BlenderMincer), A magnet stirrer used for extraction (JENWAY-1000 Hot Plate Magnetic stirrer), a vacuum rotatory evaporator used for the removal of methanol solvent from extract (vacuum rotary evaporator, KARL KOLB, Germany), a table top centrifuge (EBA 20, Hettich Zentrifugen) is used for phases separation, a double beam UV-Vis spectrophotometer (Shimadzu, Model UV1700, Japan) was employed for the measurement of absorbency throughout the experimental studies.

\section{Sample collection}

Apple fruits of different varieties in fresh condition, named: Kaja, Tor Kulu, Amri and Shin Kulu were collected from different areas of different districts of Balochistan (Ziarat, Quetta, Pishin and Kalat) based on different climates. The apple verities were further identified by Horticulture Research Department, Sariyab Road, Quetta.

\section{Sample preparation}

Firstly, samples of apple fruit were washed properly with tap water followed by peeling off with the help of a knife. After removing of seeds, the pulp and peel of the fruit were homogenized separately with the help of a juicer (Westpoint-1844-Juicer-BlenderMincer).

As the level of water content in apple fruit verities is different, all calculations were made on the basis of dry matter for dry matter determination according to a procedure reported previously [34]. The extraction and extraction yield are explained in the following paragraphs briefly.

$20 \mathrm{~g}$ homogenized fruit sample (pulp or peel) of each apple's variety was extracted with $200 \mathrm{~mL}$ of $80: 20 \%$ methanol-water mixture $(\mathrm{v} / \mathrm{v})$ at normal room temperature by using the magnetic stirrer for about 8 hours. Then 
the residue was separated from extract by filtration process through Whatman filter paper No 1 . After three extractions $(3 \times 200$ $\mathrm{mL}$ ), the excess of the methanol solvent was removed by distillation process using a vacuum rotatory evaporator at $45^{\circ} \mathrm{C}$. The resulting crude extracts were further dried with the help of a freez drier and stored at $4^{\circ} \mathrm{C}$ for further experimentation.

Following equation was used for the calculation of yield of extracts on the basis of dry weight of pulp and peel.

Yield $\left(\frac{g}{100 g}\right)=\frac{W 1}{W 2} \times 100$

Where,

$\mathrm{W}_{1}=$ weight of extracted residue after solvent removal

$\mathrm{W}_{2}=$ weight of peel or pulp taken for extraction

\section{Determination of total phenolic contents}

Total phenolics contents (TPC) in pulp and peel of apples were determined by using a well-known colorimetric technique with some modifications [35] in which FCR involves as an oxidizing agent and antioxidants in plant/fruit extracts act as reducing agent. The reduction of FCR by phenolic compounds with simultaneous formation of blue colored complex with a wavelength of maximum absorbance $\left(\lambda_{\max }\right)$ of $760 \mathrm{~nm}$. FCR measures the reducing capacity in a given sample. FCR contains hetero polyphosphotungstates-molybdates, as it gains one or two electrons from antioxidants during a redox reaction leading to the formation of a blue colored reduced complex $\left(\mathrm{PMoW}_{11} \mathrm{O}_{40}\right)$. It is believed that the $\mathrm{Mo}(\mathrm{VI})$ is easily reduced in the complex and the transfer of electrons occurs from reductants (phenolic compounds) as shown in the reaction given below:

$\mathrm{Mo}(\mathrm{VI})+\mathrm{e}^{-} \longrightarrow \mathrm{Mo}(\mathrm{V})$

The apple's peel or pulp extract $(30 \mathrm{mg} / \mathrm{mL})$ mixed well with $5 \mathrm{~mL}$ FCR (which had already been diluted 10 times with deionized water). Then $4 \mathrm{~mL}$ of $7.5 \%(\mathrm{w} / \mathrm{v})$ of $\mathrm{Na}_{2} \mathrm{CO}_{3}$ solution was added to the above mixture and incubated at $25^{\circ} \mathrm{C}$ for about 20 minutes. The absorbance of the resulted product was measured at $\lambda_{\max }$. of $760 \mathrm{~nm}$ against a reagent blank. The total phenolic contents in the samples were estimated from the regression equation obtained by the subject procedure from a calibration curve between the absorbance and a series of standards (60$300 \mu \mathrm{g} / \mathrm{mL}$ ) of gallic acid. The final results for phenolic contents in samples were calculated as $\mathrm{mg} / \mathrm{g}$ dry weight of samples.

Determination of total flavonoid contents

For the determination of total flavonoid contents (TFC) in the methanolic extract of apple's peel and pulp, a reported method with slight modifications was employed [36]. In this method, $\mathrm{Al}^{3+}$ makes a complex with hydroxyl functionality present in flavonoids which absorbs visible radiation at a $\lambda_{\max }$ of $510 \mathrm{~nm}$. For the estimation of TFC in extracts (mg/g dry weight), a regression equation obtained from the calibration curve between the absorbance intensity on the ordinate and catechin concentration (20$\left.100 \mu \mathrm{g} / \mathrm{mL} ; R^{2}=0.9978\right)$ on abscissa was employed.

In brief, the experimental procedure for TFC estimation is as: $1 \mathrm{~mL}$ of catechin standard or methanolic extract $(0.2 \mathrm{mg} / \mathrm{mL})$ diluted to $3 \mathrm{~mL}$ with methanol in a test tube followed by the addition of $5 \%(\mathrm{w} / \mathrm{v}) \mathrm{NaNO}_{2}$ aqueous solution, after $5 \mathrm{~min}, 0.3 \mathrm{~mL}$ of $10 \%(\mathrm{w} / \mathrm{v})$ $\mathrm{AlCl}_{3}$ aqueous solution and after $6 \mathrm{~min}, 2 \mathrm{~mL}$ of $1.0 \mathrm{M} \mathrm{NaOH}$. Finally, the mixture was diluted to $10 \mathrm{~mL}$ with distilled water and after incubation for $30 \mathrm{~min}$ at room temperature; the absorbance was measured spectrophotometrically at $\lambda_{\max }$. of $510 \mathrm{~nm}$ against a reagent blank.

\section{Reducing power capacity assay}

A reported method [37] with minor modification was employed for assessing the ferric reducing power of the apple's pulp and peel extracts. The generated ferrous was then coupled with ferricyanide to make a Prussian 
blue colored charge transfer complex with a $\lambda_{\max }$. of $700 \mathrm{~nm}$. The reducing activity of a substance may serve as a significant indicator for its potential antioxidants capacity.

The procedure in brief is as: $1 \mathrm{~mL}$ of either extract or ascorbic acid standards (2$10 \mathrm{mg} / \mathrm{mL}$ ) was taken in a test tube followed by the addition of $3 \mathrm{~mL}$ of $0.2 \mathrm{M}$ sodium phosphate buffer $(\mathrm{pH}=6.6), 3 \mathrm{~mL}$ of $1 \%$ $(\mathrm{w} / \mathrm{v})$ potassium ferricyanide solution, incubation at $50^{\circ} \mathrm{C}$ in a water bath for about $20 \mathrm{~min}$ and addition of $3 \mathrm{~mL}$ of trichloro acetic acid. The reaction mixture was then centrifuged at $3000 \mathrm{rpm}$ for $15 \mathrm{~min}$ and $3 \mathrm{~mL}$ of supernatant was recovered and added $3 \mathrm{~mL}$ of distilled water followed by the addition of $1 \mathrm{~mL}$ of $0.1 \%(\mathrm{w} / \mathrm{v})$ ferric chloride resulting in the appearance of Prussian blue color whose intensity was measured at $700 \mathrm{~nm}$ against a reagent blank.

\section{DPPH scavenging assay}

DPPH (2,2- Diphenyl-1-picrylHydrazyl) is a dark violet color crystalline organic compound composed of stable free radical molecules. The mechanistic approach of the method is based on the scavenging of DPPH radicals by antioxidants present either in the working standards or extract of apple and thus inhibiting the absorbance intensity at $\lambda_{\max }$ of $517 \mathrm{~nm}$. During the redox reaction, a hydrogen is donated from an antioxidant to DPPH with the simultaneous generation of reduced DPPH and its dark violet color turns into dark red to light yellow color indicating the direct antioxidant activity of either standards or samples. The reaction scheme for the redox reaction is as follows:

\section{DPPH. $+\mathrm{H}-\mathrm{A} \rightarrow$ DPPH-H + A.}

The DPPH radical scavenging capacity of the extracts and standards were measured according to a reported procedure [38] with few modifications. In brief, the determination procedure is as: $2 \mathrm{~mL}(0.4 \mathrm{mg} / \mathrm{ml})$ of fresh methanolic extract was added to a test tube containing $3 \mathrm{~mL}$ methanolic solution of DPPH $(0.004 \%$ w/v) followed by incubation in dark at room temperature for almost 30 min. Absorbance intensity of the test solution was measured at $\lambda_{\text {max. }}$ of $517 \mathrm{~nm}$ against a reagent blank. The \% inhibition activity (\%I) was calculated employing the following equation:

$\% \mathrm{I}=\left\{\left(\mathrm{A}_{0}-\mathrm{A}_{1}\right) / \mathrm{A}_{0}\right\} \times 100$

Where, $A_{o}$ is the absorbance of the control and $A_{1}$ is the absorbance of extract or standard.

\section{Statistical analysis}

Four different samples of each fruit cultivar peel and pulp separately were assayed randomly. Each sample was analyzed individually in triplicate and data are reported as Mean $(n=3) \pm \mathrm{SD}$.

\section{Results and discussion Extraction yield}

On the basis of dry weight, the peel and pulp of the studied varieties of apple yielded an appreciable amount of extractable matter with aqueous methanol. The mean extraction yield of antioxidant components was found to be $27.3 \mathrm{~g} / 100 \mathrm{~g}$ for peel and $19.1 \mathrm{~g} / 100 \mathrm{~g}$ for pulp, which showed higher extraction yield for peel than pulp. The relative major differences in the yield of peel and pulp in same fruits might be due to the variation in the chemical composition of different tissues of apple [39].

\section{Total phenolics and flavonoids contents}

The table 1 indicates the total phenolic content, calculated as Gallic Acid Equivalent (GAE), and the total flavonoids contents which was expressed as Catechin Equivalent (CE), of $80 \%$ methanolic extracts of apple's peel and pulp separately. The calibration curves obtained between the absorbencies and concentrations of gallic acid over the range of $60-300 \mu \mathrm{g} / \mathrm{mL}$ at $\lambda_{\max }$ of $760 \mathrm{~nm}$ and catechin over the range of $20-100 \mu \mathrm{g} / \mathrm{mL}$ at $\lambda_{\text {max. }}$ of $510 \mathrm{~nm}$ are shown in the figures 1 and 2 with regression equations of $y=0.007 x+$ $0.0011\left(R^{2}=0.9983\right)$ and $y=0.0036 x+0.005$ $\left(R^{2}=0.9978\right)$ respectively (where $y$ is 
absorbance intensity and $x$ is the concentration in $\mathrm{mg} / \mathrm{L}$ ).

Total phenolic contents ranged from $13.12 \mathrm{mg}$ to $17.87 \mathrm{mg} \mathrm{GAE} / \mathrm{g}$ in peel extracts and 7.21 to $11.57 \mathrm{mg}$ GAE/g in the pulp extracts of the different tested verities. Tor Kulu peel's extracts showed significantly high contents of total phenolic contents i.e. $17.87 \mathrm{mg} \mathrm{GAE} / \mathrm{g}$ as reported previously [40]. The quantity of nutrients and highly valuable components such as phenolic compounds in fruits depends upon genotypes, fruit tissues, and the maturity level of fruits, soil fertility and climatic or environmental aspects. The fruits which are not peeled have higher quantity of phenolic contents and their consumption is good for health [41].

The table 1 also shows the total flavonoid contents determined in different varieties of apple's peel and pulp. In peel extract, it was ranged from 12.22 to $15.30 \mathrm{mg} \mathrm{CE} / \mathrm{g}$ and the highest value was obtained for Tor Kulu apples i.e. $15.30 \mathrm{mg} \mathrm{CE} / \mathrm{g}$ followed by Kaja, Amri and Shin Kulu whose phenolic contents were obtained as $14.67,13.65$ and $12.89 \mathrm{mg}$ $\mathrm{CE} / \mathrm{g}$ respectively. Pulp extracts were found to have very less amount of flavonoid contents in comparison to peel. In pulp extracts the flavonoid contents ranged from 9.69mg CE/g for Tor Kulu to $6.01 \mathrm{mg} \mathrm{CE} / \mathrm{g}$ for Shin Kulu.

The considerable variation in the amounts of TPC and TFC among the four apple varieties between the peel and pulp and the results obtained in this research project are in agreement with those reported by various researchers previously [42].

These results also show that TPC and TFC variations in the same variety of apple can also be correlated with the climate variation of different areas of Balochistan. Among the four Districts of Balochistan (Ziarat, Pishin, Quetta and Kalat), the highest amount of TPC and TFC were obtained in peel and pulp extracts of all varieties of apples collected from District Ziarat (one of the coldest district of Balochistan) followed by District Pishin.

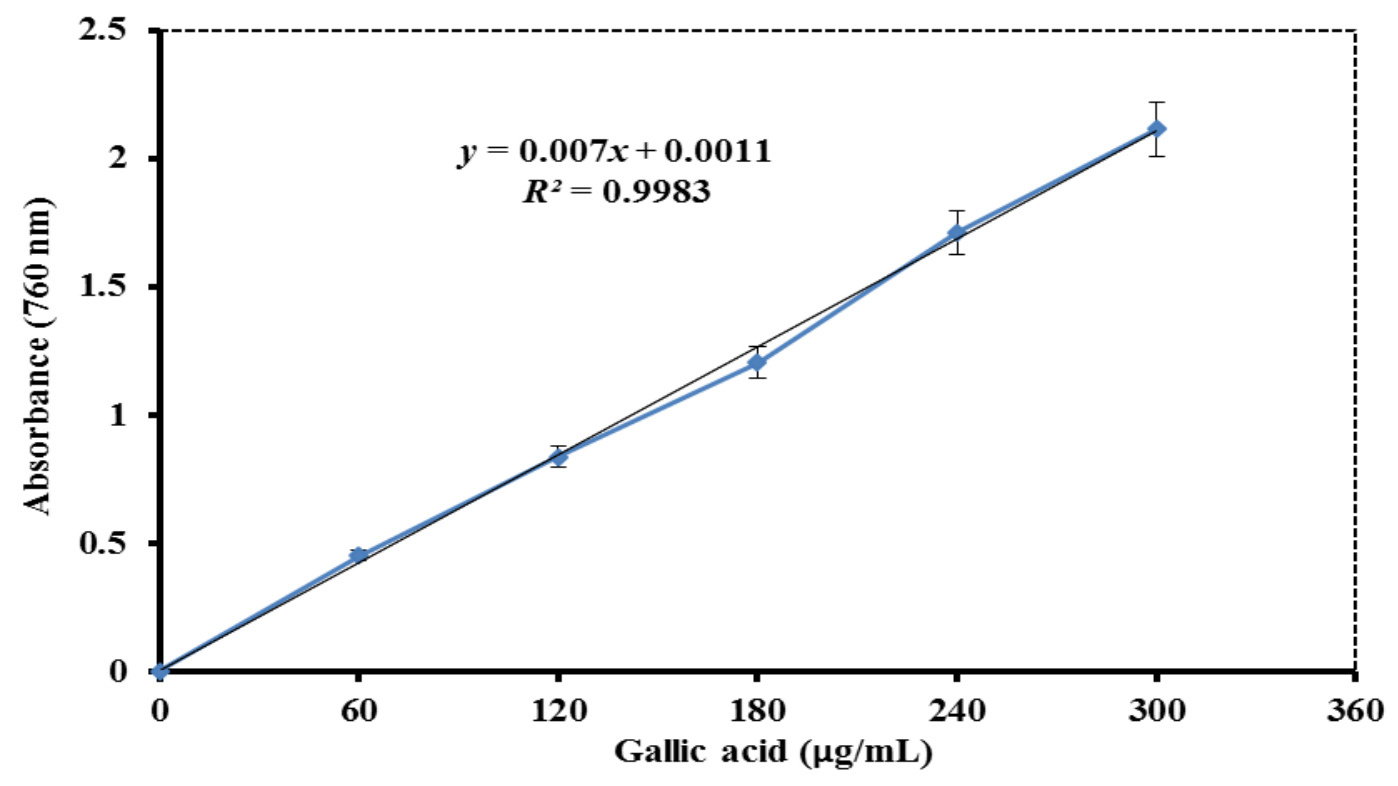

Figure 1. Standard calibration curve for gallic acid 


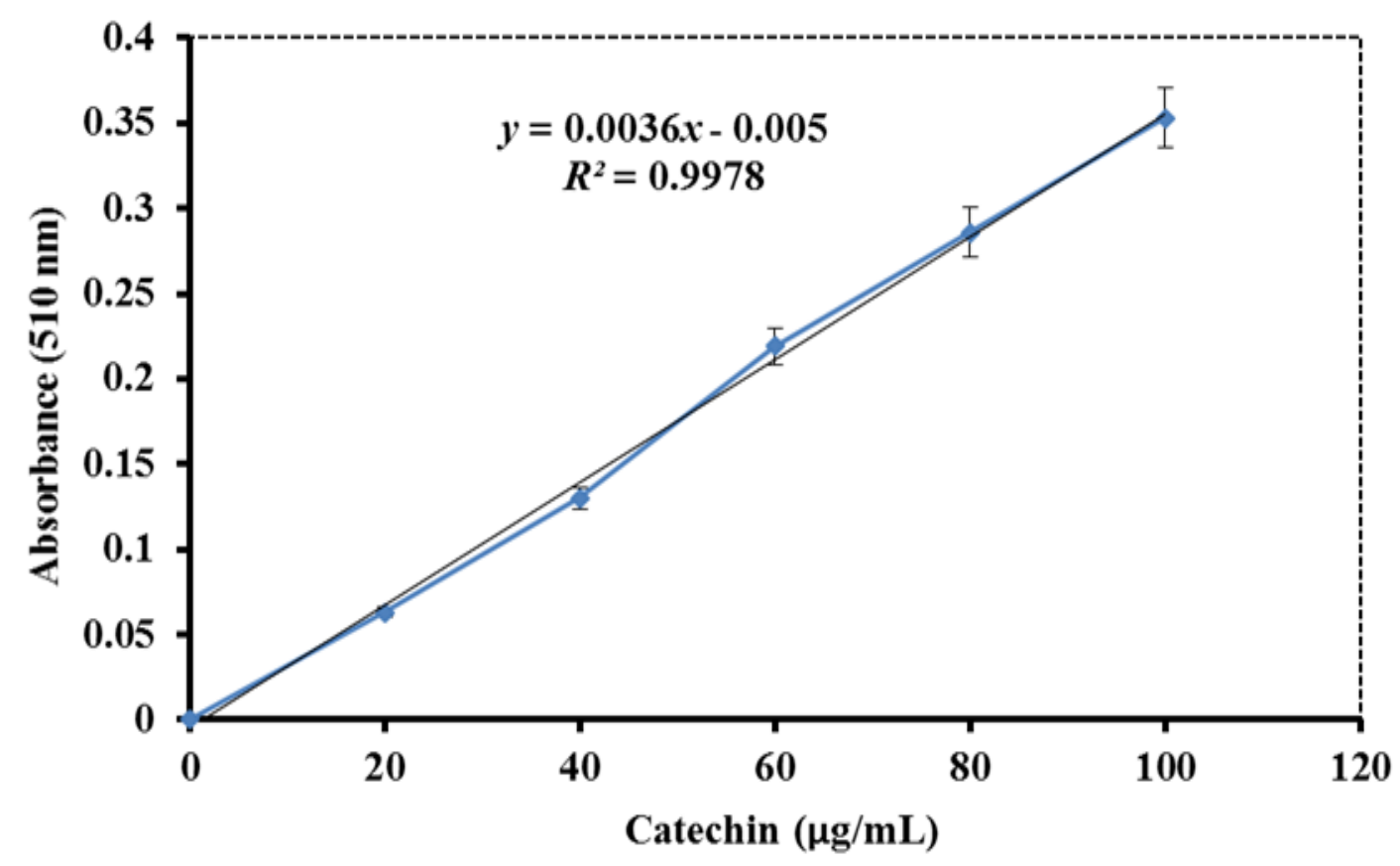

Figure 2. Standard calibration curve for catechin

Table 1. TPC \& TFC of pulp and peel extracts of different varieties of apple (Malus domestica Borkh) and sampling areas

\begin{tabular}{|c|c|c|c|c|c|}
\hline \multirow{2}{*}{$\begin{array}{c}\text { Sampling } \\
\text { area }\end{array}$} & \multirow{2}{*}{$\begin{array}{c}\text { Apple } \\
\text { variety }\end{array}$} & \multicolumn{2}{|c|}{$\begin{array}{c}\text { TPC } \\
\text { (mg GAE*/g dw } \pm \text { SD) }\end{array}$} & \multicolumn{2}{c|}{$\begin{array}{c}\text { TFC } \\
\text { (mg CE*/g dw } \pm \text { SD) }\end{array}$} \\
\cline { 3 - 6 } & & Pulp & Peel & Pulp & Peel \\
\hline Ziarat & Shin Kulu & $7.83 \pm 0.02$ & $13.76 \pm 0.14$ & $6.17 \pm 0.15$ & $12.89 \pm 0.11$ \\
\hline Pishin & Shin Kulu & $7.65 \pm 0.06$ & $13.58 \pm 0.15$ & $6.06 \pm 0.15$ & $12.70 \pm 0.17$ \\
\hline Quetta & Shin Kulu & $7.21 \pm 0.10$ & $13.12 \pm 0.22$ & $6.01 \pm 0.03$ & $12.22 \pm 0.11$ \\
\hline Kalat & Shin Kulu & $7.60 \pm 0.09$ & $13.28 \pm 0.23$ & $6.00 \pm 0.10$ & $12.46 \pm 0.16$ \\
\hline Ziarat & Amri & $9.05 \pm 0.21$ & $14.26 \pm 0.01$ & $6.63 \pm 0.17$ & $13.65 \pm 0.08$ \\
\hline Pishin & Amri & $8.50 \pm 0.17$ & $14.15 \pm 0.11$ & $6.52 \pm 0.17$ & $13.39 \pm 0.06$ \\
\hline Quetta & Amri & $8.38 \pm 0.16$ & $13.01 \pm 1.83$ & $6.11 \pm 0.11$ & $12.78 \pm 0.06$ \\
\hline Kalat & Amri & $8.43 \pm 0.17$ & $14.05 \pm 0.07$ & $6.3 \pm 0.13$ & $13.09 \pm 0.08$ \\
\hline Ziarat & Kaja & $10.12 \pm 0.39$ & $16.32 \pm 0.44$ & $7.39 \pm 0.25$ & $14.67 \pm 0.28$ \\
\hline Pishin & Kaja & $9.72 \pm 0.22$ & $16.24 \pm 0.50$ & $7.11 \pm 0.33$ & $14.41 \pm 0.34$ \\
\hline Quetta & Kaja & $9.33 \pm 0.44$ & $16.40 \pm 0.75$ & $6.37 \pm 0.38$ & $13.83 \pm 0.40$ \\
\hline Kalat & Kaja & $9.52 \pm 0.37$ & $16.13 \pm 0.59$ & $6.69 \pm 0.42$ & $14.09 \pm 0.37$ \\
\hline Ziarat & Tor Kulu & $11.57 \pm 0.08$ & $17.87 \pm 0.10$ & $9.69 \pm 0.14$ & $15.30 \pm 0.18$ \\
\hline Pishin & Tor Kulu & $10.55 \pm 0.10$ & $17.83 \pm 0.10$ & $9.50 \pm 0.11$ & $15.15 \pm 0.17$ \\
\hline Quetta & Tor Kulu & $10.27 \pm 0.11$ & $17.66 \pm 0.07$ & $9.07 \pm 0.26$ & $14.78 \pm 0.22$ \\
\hline Kalat & Tor Kulu & $10.35 \pm 0.10$ & $17.75 \pm 0.07$ & $9.35 \pm 0.12$ & $15.02 \pm 0.17$ \\
\hline
\end{tabular}

${ }^{*} \mathrm{GAE}=$ Gallic acid equivalent, $\mathrm{CE}=$ Catechin equivalent, Data are mean $\pm \mathrm{SD}(n=3 \times 3, \mathrm{P}<0.05)$

Measurement of reducing power

In this assay, the generated amount of $\mathrm{Fe}^{2+}$ as a result of the reducing power of apple extract is monitored by the measurement of the intensity of blue coloration at $700 \mathrm{~nm}$. A sample of higher absorbance value indicated 
high reducing power, thus high antioxidant activity [43].

In this procedure of reducing power measurement of the extract of apple (peel or pulp), various quantities $(2,4,6,8$ and $10 \mathrm{mg} / \mathrm{mL}$ ) of the dried residue were taken for the measurement of antioxidant activities. As the amount of the residue was increased, the increase in the absorbance intensity was also observed. Figure 3 shows the reducing power of the different extracts of different cultivars of apple. The variations in reducing power of the $10 \mathrm{mg} / \mathrm{mL}$ were ranged in peel from 2.139 to 2.725 and pulp from 1.181 to 1.724 . The reducing power capability of extracts of apple fruit (peel or pulp) of the given analysis was comparatively near to those reported in extracts of Logan fruits [44]. The reducing power capability of apple's peel extracts was higher than the pulp extracts. The reason might be the presence of higher concentration of reductants in the form of phenolic compounds present in the outer tissues (peel) of the fruits than the inner tissues (pulp) [45].

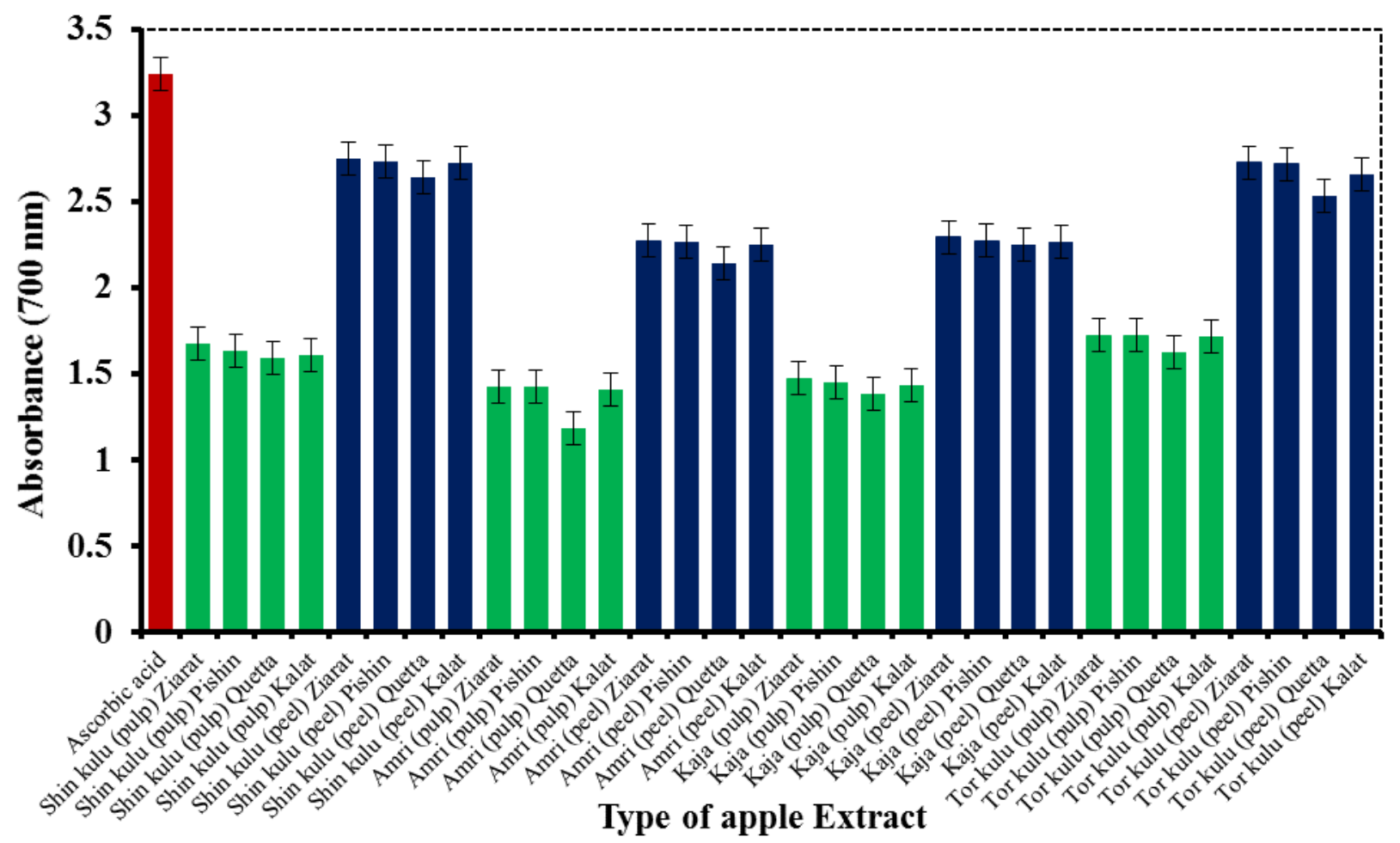

Figure 3. Reducing powers of different apple's extracts (bars indicate means $\pm \operatorname{SD}(n=3 \times$ 3))

\section{DPPH radical scavenging activity}

DPPH free radical assay is used to evaluate the scavenging capacity of antioxidants present in the plants/fruits extracts. It is a time saving assay and can be applied to analyze many samples is less time.
Moreover, this method is incredibly sensitive even at low concentration of antioxidants.

Scavenging capacity of apple peels and pulps extracts were analyzed by DPPH free radicals and compared with ascorbic acid (standards). The absorbances were recorded after 30 minutes when highest variation in scavenging 
capacity was found then that record is used for calculation. Figure 4 shows the DPPH radical scavenging capacities of different extracts of different apple varieties. The scavenging activity in all apple peel extracts were found higher, ranging from 79.6 to $67.6 \%$ compared to the apple pulp extracts, ranging from 41.2 to $57.8 \%$. Among the peel extracts of different varieties of apple, Tor Kulu exhibited the highest scavenging activity i.e. $79.6 \%$, while the Amri showed the lowest scavenging activity i.e. $67.6 \%$.

In pulp extract of different varieties, the highest scavenging activity $57.8 \%$ showed by Tor Kulu and the lowest $41.2 \%$ was recorded for Amri and the data showed close agreement with the previously reported data. In the previously reported study, $1 \mathrm{mg} / \mathrm{mL}$ residue of peel and pulp extracts have shown 78 and $55 \%$ scavenging activity respectively. It is clear from the observed results that the high DPPH radical scavenging activity in peel extracts than pulp extracts might be related to the presence of the largest quantity of antioxidants in the form of phenolic compounds and flavonoids [46].

So, the consumption of apple fruit without peel may induce loss of these valuable phytonutrients, which scavenge the free radicals and delay the cellular damage inside the bodies of living organisms.

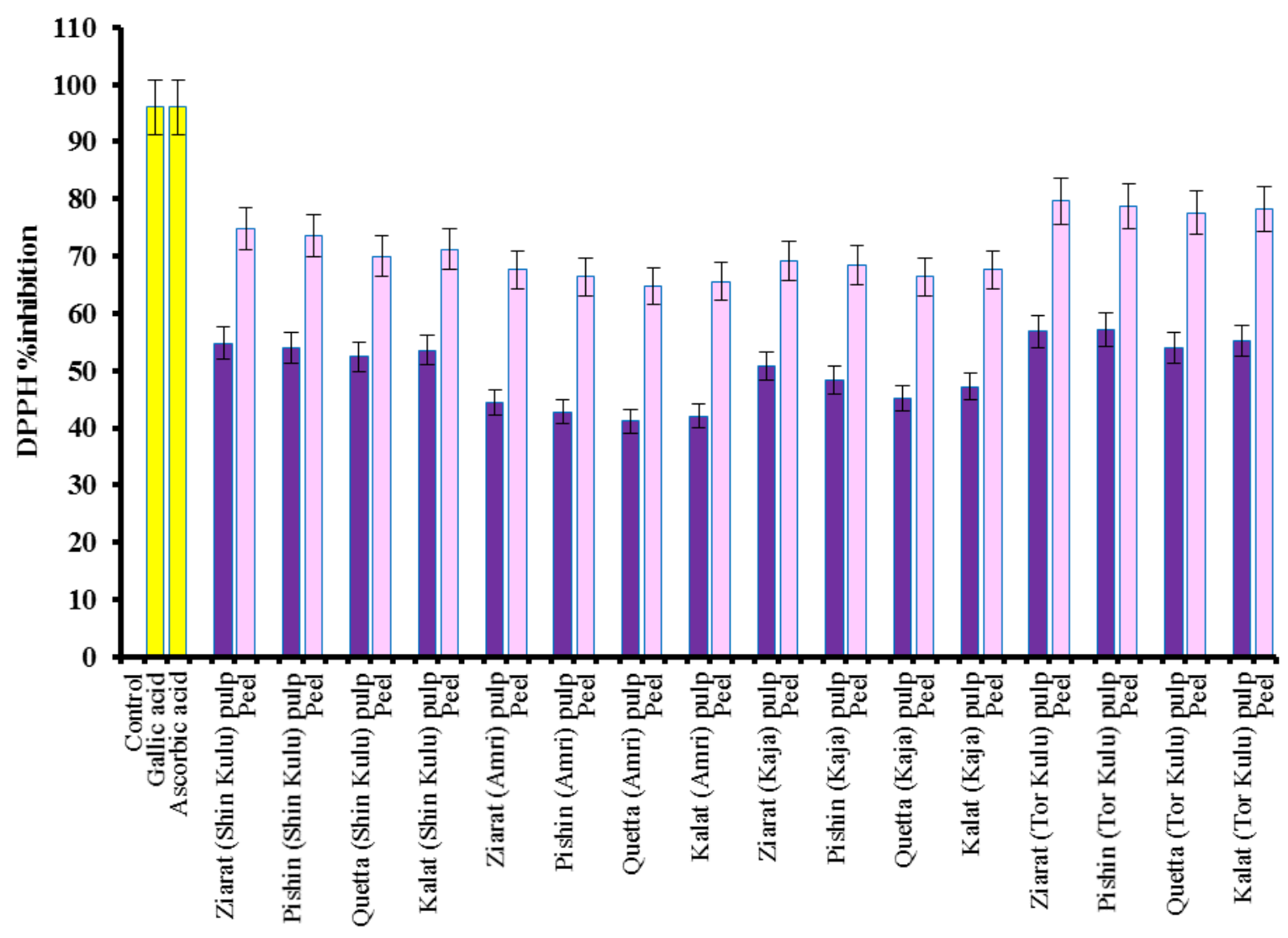

Type of apple extract

Figure 4. DPPH radical scavenging capacities of different extracts of different apple varieties (bars indicate means \pm SD $(n=3 \times 3))$ 


\section{Conclusions}

In this study, the TPC, TFC, reducing power of antioxidants and DPPH \%inhibition of peels and pulps extracts of four varieties of apple collected from the different areas of some districts of Balochistan were analyzed. The peels of all varieties were found rich in phenolic and flavonoid contents, reducing power of antioxidants and DPPH scavenging activity than pulp. Among four apple varieties analyzed, Tor Kulu was found to be rich in all these measured variables comparing to other varieties. Based on the obtained results, it is concluded that apple peel removal may provoke for loss of considerable nutrients. As with many other fruits and vegetables, apple consumption along with peel could provide more nutritional and health benefits.

\section{Authors' contributions}

Conceived and designed the experiments: A Muhammad, AU Rehman \& Samiullah, Performed the experiments: A Muhammad, AU Rehman, A Baqi \& Hayatullah, Analyzed the data: AU Rehman, N Khan \& Samiullah, Contributed materials/ analysis/ tools: M Asghar, AJ Zeerak \& M Hussain, Wrote the paper: A Muhammad, AU Rehman, Samiullah \& A Baqi.

\section{References}

1. Lobo V, Patil A, Phatak A \& Chandra N (2010). Free radicals, antioxidants and functional foods: Impact on human health. Phcog Rev 4(8): 118-126.

2. Phaniendra A, Jestadi DB \& Periyasamy L (2015). Free radicals: properties, sources, targets, and their implication in various diseases. Indian $J$ Clin Biochem 30(1): 11-26.

3. Droge W (2002). Free radicals in the physiological control of cell function. Physiol Rev 82(1): 47-95.

4. Valko M, Leibfritz D, Moncol J, Cronin MT, Mazur M \& Telser J (2007). Free radicals and antioxidants in normal physiological functions and human disease. Int J Biochem Cell Biol 39(1): 44-84.

5. Oliveira BF, Nogueira-Machado JA \& Chaves MM (2010). The role of oxidative stress in the aging process. $S c i$ World J 10: 1121-1128.

6. Roy J, Galano JM, Durand T, Le Guennec JY \& Lee JCY (2017). Physiological role of reactive oxygen species as promoters of natural defenses. The FASEB Journal 31(9): 3729-3745.

7. Kumar S (2011). Free radicals and antioxidants: human and food system. Adv Appl Sci Res 2(1): 129-135.

8. Pisoschi AM \& Negulescu GP (2011). Methods for total antioxidant activity determination: A review. Biochem Anal Biochem 1(1): 106.

9. Raman ST, Ganeshan AKPG, Chen C, Jin C, Li SH, Chen HJ \& Gui Z (2016). In vitro and in vivo antioxidant activity of flavonoid extracted from mulberry fruit (Morus alba L). Pharmacogn Mag 12(46): 128.

10. Kim YW \& Byzova TV (2014). Oxidative stress in angiogenesis and vascular disease. Blood 123(5): 625-631.

11. Pham Huy LA, He H \& Pham Huy C (2008). Free radicals, antioxidants in disease and health. Int J Biomed Sci 4(2): 89.

12. Shahidi F, \& Zhong Y (2010). Novel antioxidants in food quality preservation and health promotion. Eur J Lipid Sci Technol 112(9): 930-940.

13. Pandey KB \& Rizvi SI (2009). Plant polyphenols as dietary antioxidants in human health and disease. Oxid Med Cell Longev 2(5): 270-278.

14. Oliveira MR, Fogaca KC \& LeandroMerhi VA (2009). Nutritional 
status and functional capacity of hospitalized elderly. Nutr J 8(1): 54.

15. Scalzo J, Politi A, Pellegrini N, Mezzetti B \& Battino M (2005). Plant genotype affects total antioxidant capacity and phenolic contents in fruit. Nutrition 21(2): 207-213.

16. Manzoor M, Anwar F, Saari N \& Ashraf M (2012). Variations of antioxidant characteristics and mineral contents in pulp and peel of different apple (Malus domestica Borkh) cultivars from Pakistan. Molecules 17(1): 390-407.

17. Ramadan Hassanien MF (2008). Total antioxidant potential of juices, beverages and hot drinks consumed in Egypt screened by DPPH in vitro assay. Grasas $y$ aceites 59(3): 254-259.

18. Hyson DA (2011). A comprehensive review of apples and apple components and their relationship to human health. Adv Nutr 2(5): 408-420.

19. Boyer J \& Liu RH (2004). Apple phytochemicals and their health benefits. Nutr J 3(1): 1-15.

20. Huber GM \& Rupasinghe HPV (2009). Phenolic profiles and antioxidant properties of apple skin extracts. J Food Sci 74(9): C693-C700.

21. Lata B, Trampczynska A \& Paczesna J (2009). Cultivar variation in apple peel and whole fruit phenolic composition. Sci Hortic 121(2): 176-181.

22. Flood Obbagy JE \& Rolls BJ (2009). The effect of fruit in different forms on energy intake and satiety at a meal. Appetite 52(2): 416-422.

23. Cho KD, Han CK \& Lee BH (2013). Loss of body weight and fat and improved lipid profiles in obese rats fed apple pomace or apple juice concentrate. J Med Food 16(9): 823-830.

24. Majewska WM \& Czeczot H (2012). Flavonoids in the prevention and treatment of cardiovascular diseases. Pol Merkur Lekarski 32(187): 50-54.
25. Koutsos A, Tuohy $\mathrm{K}$ \& Lovegrove $\mathbf{J}$ (2015). Apples and cardiovascular health - is the gut microbiota a core consideration? Nutrients 7(6): $3959-$ 3998.

26. Song Y, Manson JE, Buring JE, Sesso HD \& Liu S (2005). Associations of dietary flavonoids with risk of type 2 diabetes, and markers of insulin resistance and systemic inflammation in women: a prospective study and crosssectional analysis. J Am Coll Nutr 24(5): 376-384.

27. Mlcek J, Jurikova T, Skrovankova S \& Sochor J (2016). Quercetin and its antiallergic immune response. Molecules 21(5): 1-15.

28. Gerhauser C (2008). Cancer chemopreventive potential of apples, apple juice and apple components. Planta Med 74(13): 1608-1624.

29. Prynne CJ, Mishra GD, O’Connell MA, Muniz G, Laskey MA, Yan L \& Ginty F (2006). Fruit and vegetable intakes and bone mineral status: a cross-sectional study in 5 age and sex cohorts. Am J Clin Nutr 83(6): 1420-1428.

30. Rogers EJ, Milhalik S, Orthiz D \& Shea TB (2004). Apple juice prevents oxidative stress and impaired cognitive performance caused by genetic and dietary deficiencies in mice. $J$ Nutr Health Aging 8(2): 92-97.

31. GOP (2013). Government of Pakistan, Economic Survey of Pakistan, Economic Advisory Wing, Finance Division, Islamabad.

32. Noonari S, Memon MIN, Wahid R, Peerzdo MB, Bhatti MA \& Kalwar GY (2015). Economic Analysis of Apple Orchards Production in District Mastung Balochistan Pakistan. Europ J Bus Manage 7(10) 40-53.

33. Shah NA, Afzal M, Ahmed M, Ahmad QB, Farooq A \& Rehman FU (2011). Marketing of apple in Northern 
Balochistan. Sarhad J Agric 27(4): 617624.

34. Chemists AA \& Horwitz W (1990). Official methods of analysis. Vol. I. 15th ed. AOAC, Arlington, VA.

35. Bahukhandi A, Dhyani P, Bhatt ID \& Rawal RS (2018). Variation in Polyphenolics and Antioxidant Activity of Traditional Apple Cultivars from West Himalaya, Uttarakhand. Hortic Plant J 4(4): 151-157.

36. Zhishen J, Mengcheng T \& Jianming W (1999). The determination of flavonoid contents in mulberry and their scavenging effects on superoxide radicals. Food chem 64(4): 555-559.

37. Lim YY, Lim TT \& Tee JJ (2007). Antioxidant properties of several tropical fruits: A comparative study. Food chem 103(3): 1003-1008.

38. Gour RK \& Anthony P (2015). Evaluation of Antioxidant Activity of Apple Peel and Pulp Extracts by Using Different Solvents. Chem Sci Trans 4(3): 723-727.

39. Li Y, Guo C, Yang J, Wei J, Xu J \& Cheng S (2006). Evaluation of antioxidant properties of pomegranate peel extract in comparison with pomegranate pulp extract. Food chem 96(2): 254-260.

40. Kuti JO (2004). Antioxidant compounds from four Opuntia cactus pear fruit varieties. Food chem 85(4): 527-533.

41. Henriquez C, Almonacid S, Chiffelle I,
Valenzuela T, Araya M, Cabezas L \& Speisky H (2010). Determination of antioxidant capacity, total phenolic content and mineral composition of different fruit tissue of five apple cultivars grown in Chile. Chil $\mathrm{J} \mathrm{Agr}$ Res 70(4): 523-536.

42. Vieira FGK, Borges GDSC, Copetti C, Amboni RDDMC, Denardi F \& Fett R (2009). Physico-chemical and antioxidant properties of six apple cultivars (Malus domestica Borkh) grown in southern Brazil. Sci Hortic 122(3): 421-425.

43. Pan Y, He C, Wang H, Ji X, Wang K \& Liu P (2010). Antioxidant activity of microwave-assisted extract of Buddleia officinalis and its major active component. Food Chem 121(2): 497502.

44. Prasad KN, Yang B, Zhao M, Sun J, Wei X \& Jiang Y (2010). Effects of high pressure or ultrasonic treatment on extraction yield and antioxidant activity of pericarp tissues of longan fruit. $J$. Food Biochem 34(4): 838-855.

45. Abrosca B, Pacifico S, Cefarelli G, Mastellone C \& Fiorentino A (2007). 'Limoncella' apple, an Italian apple cultivar: Phenolic and flavonoid contents and antioxidant activity. Food chem 104(4): 1333-1337.

46. Wolfe K, Wu X \& Liu RH (2003). Antioxidant activity of apple peels. $J$ Agric Food Chem 51: 609-614. 